\title{
Protective effects of peel and seed extracts of Citrus aurantium on glutamate-induced cytotoxicity in PC12 cell line
}

\author{
Azar Hosseini ${ }^{1}$, Hamid Reza Sadeghnia ${ }^{1,2,3}$, Arezoo Rajabian ${ }^{2}$ \\ ${ }^{1}$ Pharmacological Research Center of Medicinal Plants, Mashhad University of Medical Sciences, Mashhad, ${ }^{2}$ Department \\ of Pharmacology, School of Medicine, Mashhad University of Medical Sciences, Mashhad, ${ }^{3}$ Neurocognitive Research Center, \\ School of Medicine, Mashhad University of Medical Sciences, Mashhad, Iran
}

\begin{abstract}
Oxidative stress and apoptosis contribute to neuronal degeneration in many neurodegenerative diseases such as Alzheimer's disease. Glutamate is a major excitatory neurotransmitter in the central nervous system (CNS) and is considered responsible for the pathogenesis of many neurological disorders. Reactive oxygen species (ROS) production is thought to be involved in glutamate-induced apoptosis process. In this study, the neuroprotective effects of Citrus aurantium in the glutamate-induced rat's adrenal pheochromocytoma cell line (PC12 cells) were investigated. The cell viability and apoptotic cell death were measured using MTT and propidium iodine (PI)-staining methods, respectively. In addition, intracellular ROS and malondialdehyde (MDA) levels were determined by fluorometric methods. The results showed that glutamate cytotoxicity in PC12 cells was accompanied by an increment of MDA content, ROS generation, and apoptotic induction. However, pretreatment with peel and seed extracts of C. aurantium significantly reduced MDA content, ROS generation, and apoptotic cells. All these findings indicated that $C$. aurantium protected $P C 12$ cells against glutamate-induced apoptosis by inhibiting ROS production. Therefore, the present study supports that $C$. aurantium extracts possess neuroprotective effects against glutamate-induced toxicity in PC12 cell line. The protective effect of $C$. aurantium might be attributed to its antioxidant properties.
\end{abstract}

Key words: apoptosis, Citrus aurantium, glutamate cytotoxicity, neuroprotection, PC12.

\section{Introduction}

Glutamate is the most excitatory neurotransmitter in the brain. It is an important neurotransmitter for learning and memory in the central nervous system [32]. Excessive amounts of glutamate may act as a potent neurotoxin by activating the proteolytic enzymes [39]. Naturally, glutamate is released into the synaptic cleft and binds to glutamate receptors resulting in the propagation of an action potential
[22]. However, increased amounts of glutamate in the synaptic cleft can lead to neurotoxicity. It has been reported that glutamate increases in patients who suffer from Alzheimer's disease [11]. PC12 cell line is derived from a pheochromocytoma of rat adrenal medulla. This cell model is also widely applied to study cellular glutamate toxicity [38]. Therefore, it is an appropriate model to investigate the protective effect of the compounds on glutamate toxicity. Citrus aurantium L. (Rutaceae), also called 
Bitter orange, has been used as a traditional medicine for more than 5,000 years [5]. Citrus fruits and their products are rich sources of health-promoting constituents and are widely consumed around the world [5]. They increase serum antioxidant capacity against lipid peroxidation [3] and reduce the elderly oxidative stress. Citrus flavonoids have been shown to prevent oxidative stress, attenuate inflammation and exhibit anti-tumor [31,33] and anti-atherosclerosis properties [27]. In addition, citrus fruits serve as a supplement of chemotherapy [26], diabetic health food [2], and neuroprotection [15]. Furthermore, the aqueous extract from the leaves of the $C$. aurantium have anticonvulsant properties [34]. Considering the antioxidant properties, this research focuses on protective effects of peel and seed extracts of $C$. aurantium against glutamate toxicity in PC12 cells.

\section{Material and methods \\ Reagents and chemicals}

3-(4,5-dimethylthiazol-2-yl)-2,5-diphenyl tetrazolium (MTT), thiobarbituric acid (TBA), 2,7-dichlorofluorescin diacetate (DCFH-DA), propidium iodide (PI), sodium citrate and Triton X-100 were purchased from Sigma (St. Louis, MO, USA). High-glucose Dulbecco's Modified Eagles Medium (DMEM), penicillin-streptomycin, and fetal bovine serum were purchased from Gibco (Carlsbad, CA, USA). Trichloroacetic acid (TCA), malondialdehyde bis(dimethyl acetal) (MDA) and dimethyl sulfoxide (DMSO) were obtained from Merck (Darmstadt, Germany). PC12 cells were obtained from Pasteur Institute (Tehran, Iran).

\section{Preparation of the extracts}

Peels and seeds of $C$. aurantium were washed, dried, and crushed to powder with an electric micronizer. The peels and seeds were extracted separately in a Soxhlet extractor with ethanol (70\%) and the obtained extract was then dried and kept at $-20^{\circ} \mathrm{C}$ until use. The obtained extracts were dissolved in dimethyl sulfoxide and then subjected to cytotoxic and apoptosis assays.

\section{Cell culture and treatment}

The cells were maintained at $37^{\circ} \mathrm{C}$ in a humidified atmosphere containing $5 \% \mathrm{CO}_{2}$. The cells were then cultured in Dulbecco's Modified Eagles Medium (DMEM) supplemented with $10 \%$ fetal bovine serum, 100 Units $/ \mathrm{ml}$ penicillin and $100 \mu \mathrm{g} / \mathrm{ml}$ streptomycin.
For the experiments, they were seeded in 96-well and 24-well culture plates for MTT/ROS and MDA assays, respectively. For apoptosis assay, the cells were seeded at 100,000 cell/well in a 24 -well plate. All treatments were carried out in triplicate. The cells were pretreated with the extract alone ( 6 to $200 \mu \mathrm{g} / \mathrm{ml}$ ) for $2 \mathrm{~h}$ and then incubation was continued in the presence of the extract with or without $8 \mathrm{mM}$ glutamate for $24 \mathrm{~h}$.

\section{Cell viability assay}

Cell viability was determined using a modified MTT assay as described previously [13]. Briefly, MTT solution in phosphate-buffered saline $(5 \mathrm{mg} / \mathrm{ml})$ was added to each well at a final concentration of $0.05 \%$. After $3 \mathrm{~h}$, the formazan precipitate was dissolved in DMSO. The absorbance of 570 and $620 \mathrm{~nm}$ (background) was measured using a StatFAX303 plate reader.

\section{Lipid peroxidation assay}

The level of lipid peroxidation was estimated by measuring MDA, which is the end product of lipid peroxidation [13]. At the end of incubation, the cells were scraped and centrifuged for $30 \mathrm{~min}$. Then, $400 \mu \mathrm{l}$ of TCA (15\%) and $800 \mu$ of TBA (0.7\%) were added to $500 \mu \mathrm{l}$ of cell samples. The mixture was vortexed and heated for $40 \mathrm{~min}$ in a boiling water bath. Then, $200 \mu \mathrm{l}$ of the sample was transferred to a 96-well plate and the fluorescence intensity was read with excitation/ emission of $480 / 530 \mathrm{~nm}$. The experiment was carried out in triplicate.

\section{Measurement of reactive oxygen species}

The intracellular ROS level was evaluated using a fluorescent probe, DCFH-DA. At the end of incubation, the cells were treated (30 min) with DCFH-DA $(10 \mu \mathrm{M})$ at $4^{\circ} \mathrm{C}$ in the dark. Then, the fluorescence intensity was detected with excitation/emission of $485 / 530 \mathrm{~nm}$. The experiment was performed in triplicate.

\section{Propidium iodine staining}

Apoptotic cells were detected using PI staining of small DNA fragments followed by flow cytometry. In the cells exposed to a hypotonic phosphate-citrate buffer containing $\mathrm{PI}$, a quantitative DNA-binding dye, a sub-G1 peak is reflective of the DNA fragmentation. Apoptotic cells that had lost DNA will take up less stain and appear on the left side of the G1 peak in the histogram. Briefly, the cells were seeded 
in a 24-well plate and treated according to the mentioned protocol. Floating and adherent cells were then harvested and incubated at $4^{\circ} \mathrm{C}$ overnight in the dark with $750 \mu$ l of a hypotonic buffer $(50 \mu \mathrm{g} / \mathrm{ml}$ $\mathrm{PI}$ in $0.1 \%$ sodium citrate with $0.1 \%$ Triton $\mathrm{X}-100)$. Next, flow cytometry was carried out using a FACScan flow cytometer (Becton Dickinson). A total of $10^{4}$ events were achieved with FACS.

\section{Statistics}

All the data were expressed as mean \pm SEM. Statistical analyses were performed using Prism 6 software. Data were analyzed using one-way analysis of variance followed by Tukey-Kramer post hoc test for comparison between groups. The differences were considered significant at $p<0.05$.

\section{Results}

\section{The effect of the peel and seed extracts on the cell viability}

To study the possible toxic effects of the extracts, PC12 cells were incubated with different concentrations of the extracts $(12-200 \mu \mathrm{g} / \mathrm{ml})$, and the viability was determined $24 \mathrm{~h}$ after the treatment. No significant toxic effect on the cell viability was seen subsequent to the treatment with the extracts.

Incubation with glutamate significantly decreased cell viability to $43.7 \pm 1.4 \%$ of control $(p<0.001)$. As shown in Figure $1 \mathrm{~A}$, the treatment with the peel extract increased cell viability following glutamate insult at a concentration of $25-200 \mu \mathrm{g} / \mathrm{ml}$, in a con-

A

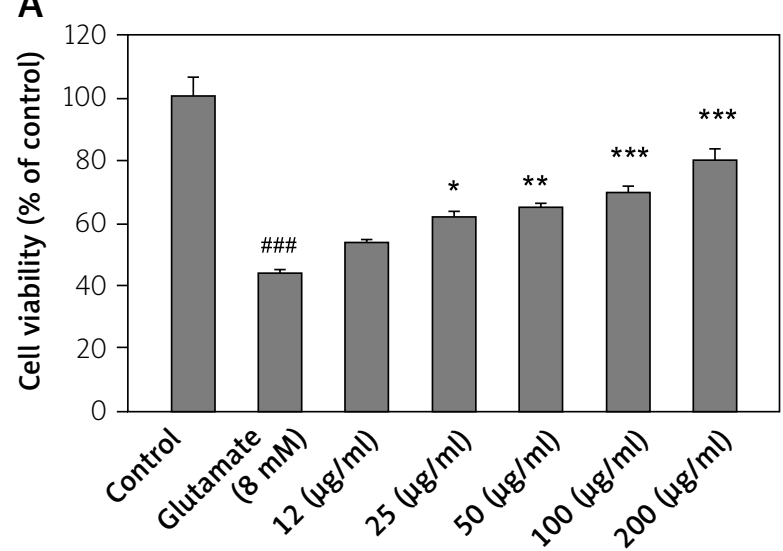

centration-dependent manner $(25 \mu \mathrm{g} / \mathrm{ml}, 61.36 \pm 2 \%$, $p<0.05 ; 50 \mu \mathrm{g} / \mathrm{ml}, 64.62 \pm 1 \%, p<0.01 ; 100 \mu \mathrm{g} /$ $\mathrm{ml}, 69.62 \pm 1.9 \%, p<0.001 ; 200 \mu \mathrm{g} / \mathrm{ml}, 80 \pm 3.7 \%$, $p<0.001)$. Moreover, the results showed that the seed extract increased cell viability at the concentrations of $50-200 \mu \mathrm{g} / \mathrm{ml}(50 \mu \mathrm{g} / \mathrm{ml}, 63 \pm 1.6 \%, p<0.01$; $100 \mu \mathrm{g} / \mathrm{ml}, 65 \pm 0.98 \%, p<0.001 ; 200 \mu \mathrm{g} / \mathrm{ml}, 70 \pm 1.9 \%$, $p<0.001$ ) (Fig. 1B).

\section{The effects of the peel and seed extracts on ROS content}

As expected, glutamate caused a significant increase in the level of ROS in PC12 cells (260 $\pm 7.8 \%$ of control, $p<0.001)$. The peel extract at concentrations of 50,100 and $200 \mu \mathrm{g} / \mathrm{ml}$ was able to decrease the intracellular ROS level to $219.8 \pm 10.37 \%(p<0.05)$, $206 \pm 7.8 \%(p<0.01)$ and $152 \pm 6.7 \%(p<0.001)$ of control, respectively (Fig. 2A). The seed extract decreased the ROS level at concentrations of $100 \mu \mathrm{g} / \mathrm{ml}$ $(212 \pm 5.2 \%, p<0.01)$ and $200 \mu \mathrm{g} / \mathrm{ml}(189 \pm 7.6 \%$, $p<0.001$ ) (Fig. 2B).

\section{The effect of the peel and seed extracts on lipid peroxidation}

The level of lipid peroxidation was evaluated by measuring the level of MDA, which is the end product of lipid peroxidation. As shown in Figure 3, exposure of the cells to glutamate resulted in a significant increase of MDA level $(269 \pm 7.5 \%, p<0.001)$ as compared to control cells cultured in the absence of glutamate $(100 \pm 4.5 \%)$. The content of MDA signifi-

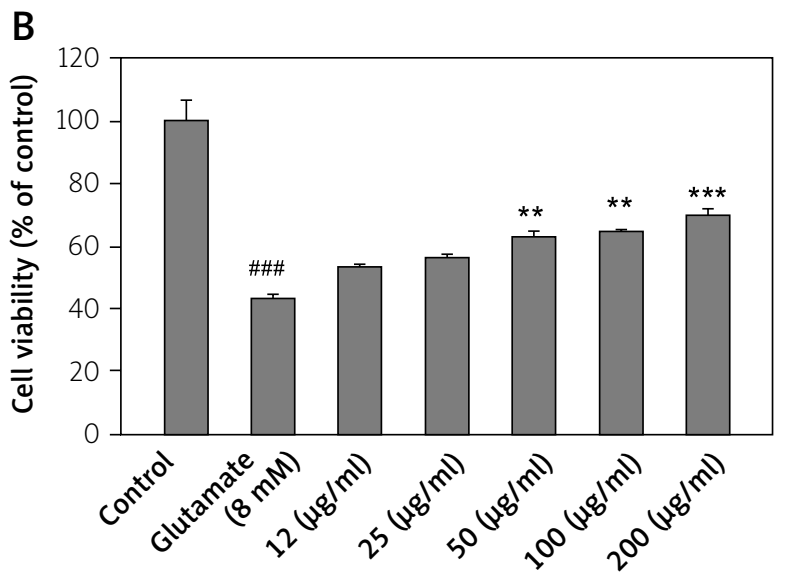

Fig. 1. Effect of Citrus aurantium extracts on cell viability of PC12 cells. The cells were pretreated with different concentrations of the peel (A) and seed (B) extracts for $2 \mathrm{~h}$ prior to glutamate exposure. Viability was quantitated using MTT assay. Results are mean \pm SEM $(n=3)$. ${ }^{\# \#} p<0.001$ vs. control, ${ }^{*} p<0.05,{ }^{* *} p<0.01$ and ${ }^{* * *} p<0.001$ vs. glutamate. 
cantly decreased in the cells pretreated with $50 \mu \mathrm{g} /$ $\mathrm{ml}(222.4 \pm 11.3 \%, p<0.001), 100 \mu \mathrm{g} / \mathrm{ml}(194 \pm 6.86 \%$, $p<0.001)$ and $200 \mu \mathrm{g} / \mathrm{ml}(147 \pm 8.4 \%, p<0.001)$ of the skin extract (Fig. 3A). The seed extract reduced the level of MDA at $100 \mu \mathrm{g} / \mathrm{ml}(206 \pm 7.5 \%, p<0.05)$ and $200 \mu \mathrm{g} / \mathrm{ml}(160 \pm 8.4 \%, p<0.001)$ (Fig. 3B).

\section{The effects of the peel and seed extracts on apoptotic cells}

Apoptosis in PC12 cell line was detected with flow cytometry using PI staining. Cells were pretreated for $2 \mathrm{~h}$ with various concentrations of the $C$. aurantium and exposed to glutamate for $24 \mathrm{~h}$. Analysis of the sub-G1 peak in flow cytometry histograms revealed the induction of apoptosis in the cells treated with glutamate $(p<0.001)$. As shown in Figure $4 \mathrm{~A}$ and $4 \mathrm{~B}$, the peel and the seed extracts of $C$. aurantium decreased apoptotic induction significantly at the doses of 50,100 and $200 \mu \mathrm{g} / \mathrm{ml}$, respectively.

\section{Discussion}

The present study is the first report to evaluate neuroprotective effects of peel and seed extracts of C. aurantium against apoptotic cell death induced by glutamate toxicity in PC12 cells. After treating PC12 cells with $8 \mathrm{mM}$ glutamate, a significant decrease in the cell viability and increase in the number of apoptotic cells, ROS and MDA contents were seen, confirming its neurotoxic effect on PC12 cells. PC12 cells were used because they constitute a widely-

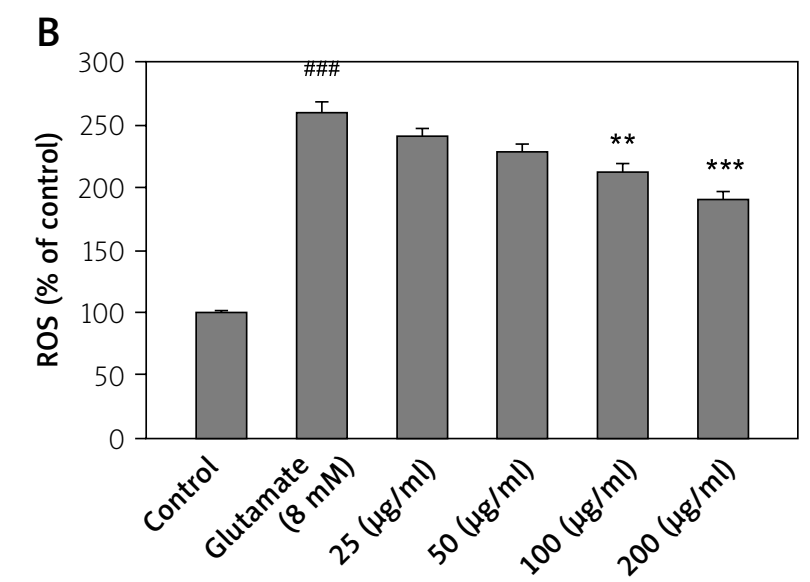

A

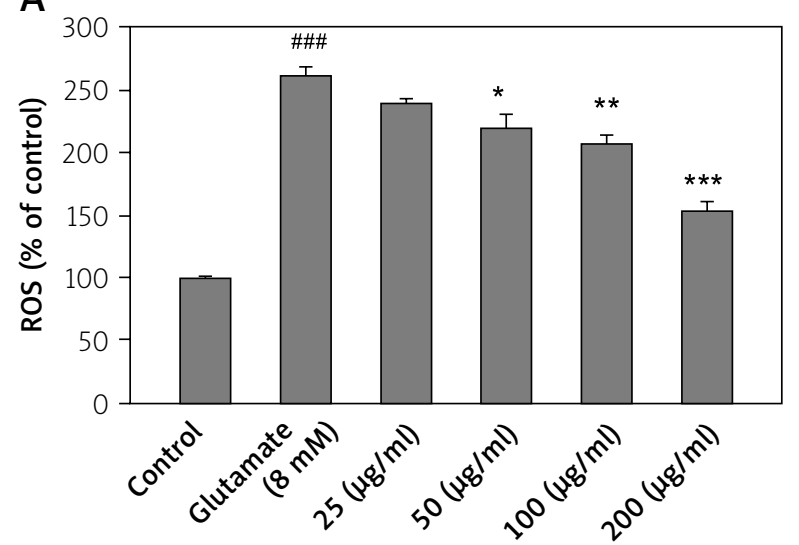

Fig. 2. Effect of Citrus aurantium extracts on ROS generation. The cells were pretreated with different concentrations of the peel (A) and seed (B) extracts for $2 \mathrm{~h}$ prior to glutamate exposure. Results are mean \pm SEM

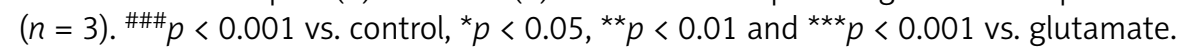

A

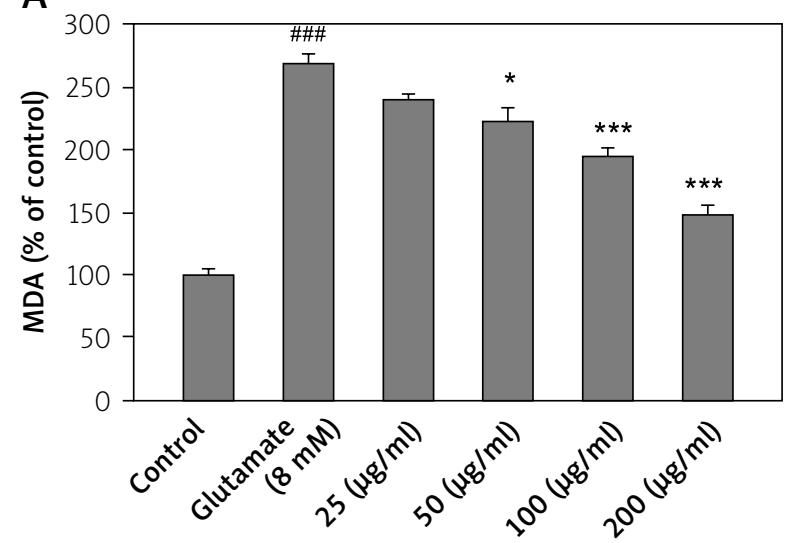

B

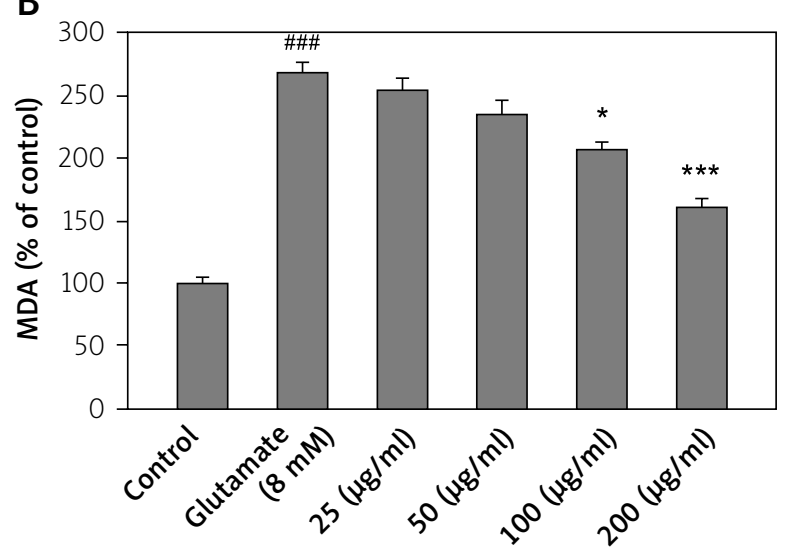

Fig. 3. Effect of Citrus aurantium extracts on MDA production. The cells were pretreated with different concentrations of the peel (A) and seed (B) extracts for $2 \mathrm{~h}$ then prior to glutamate exposure. Results are mean

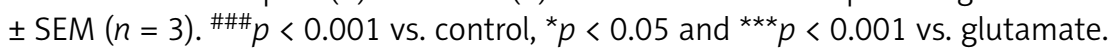


A
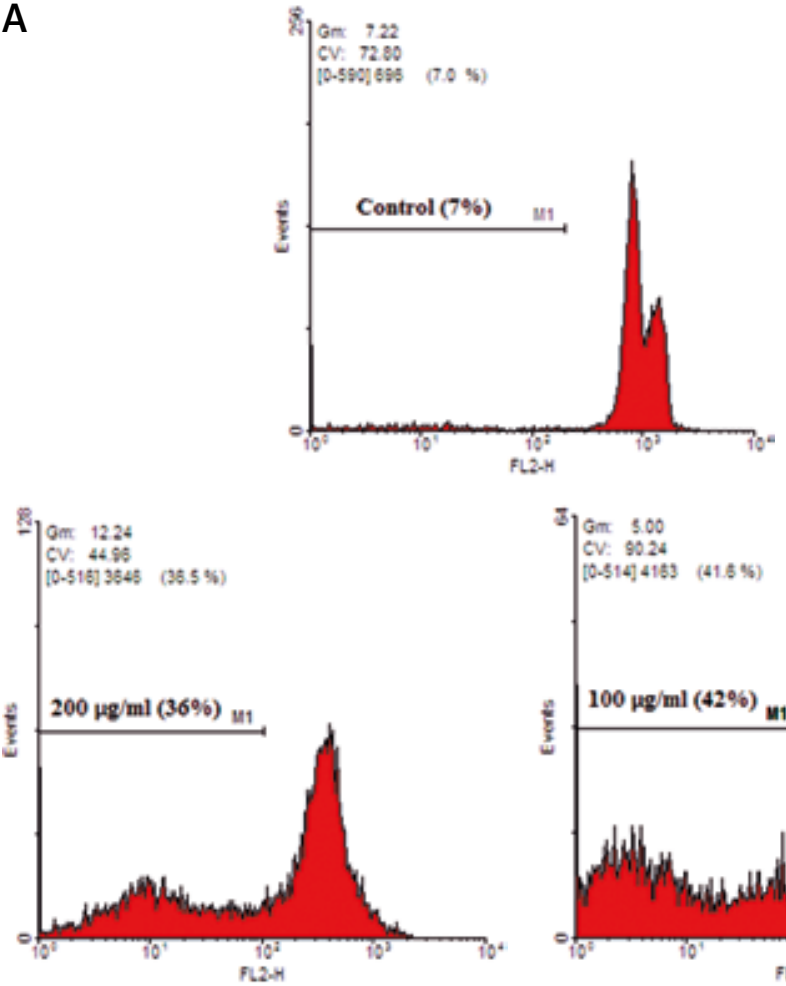

B
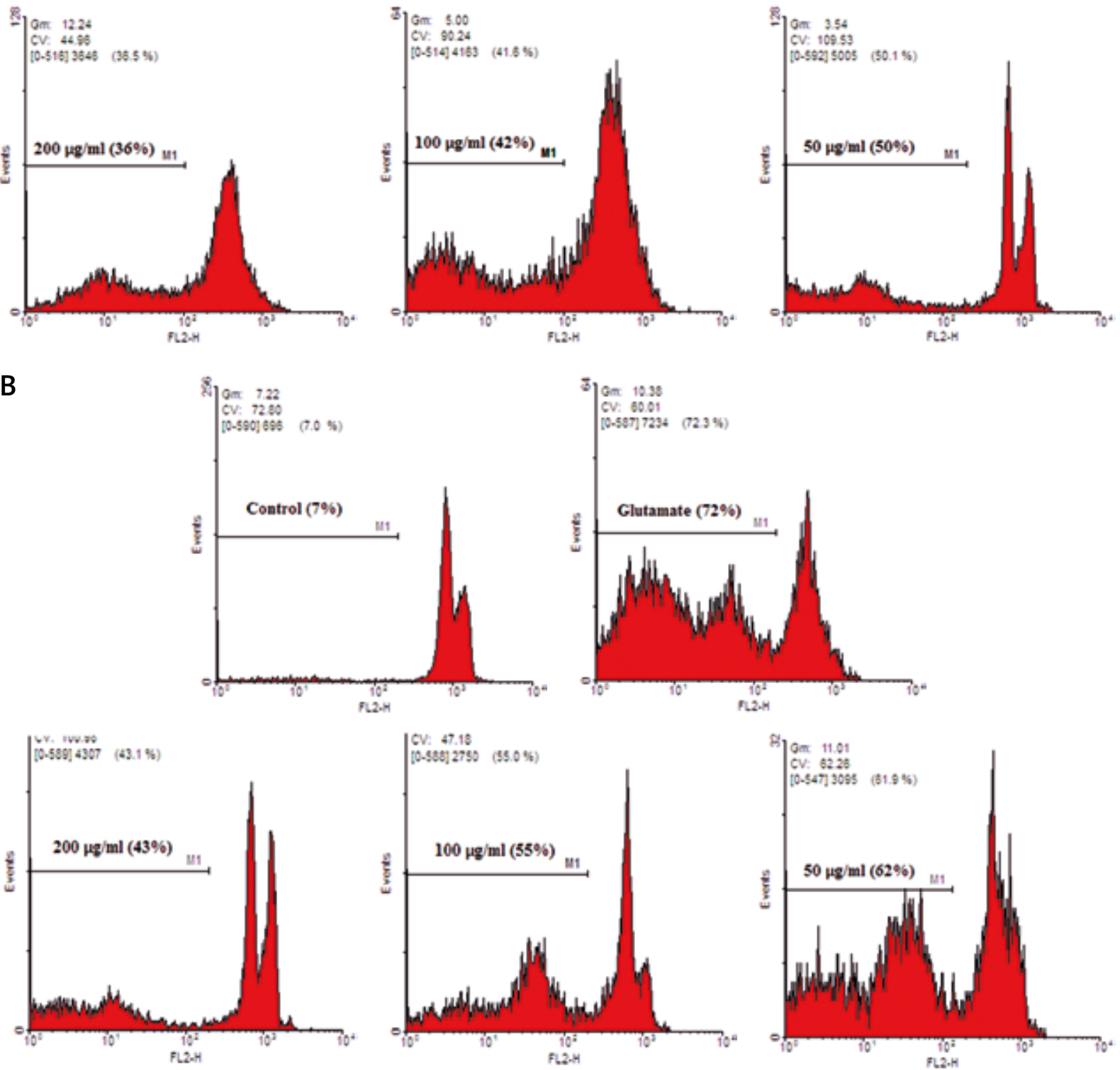

Fig. 4. The effects of the peel (A) and seed (B) extracts of Citrus aurantium extracts on apoptosis in PC12 cells using propidium iodine staining and flow cytometry. 
used neuronal model system [17]. PC12 cells are more sensitive to glutamate injury; therefore, this cell model is also widely applied to study cellular glutamate toxicity [38]. Results showed that the pretreatment with $C$. aurantium peel and seed extracts can decrease glutamate-toxicity with different potencies. Our findings indicated that the peel extract has a more protective effect than the seed extract. Glutamate, a major excitatory neurotransmitter, plays an important role in synaptic transmission, formation of neuronal circuit, and neuronal development in the nervous system [37]. The elevated level of glutamate due to excess release or/and uptake disorder led to induce extensive neuronal damage and cell loss in brain tissue. Glutamate cytotoxicity has been associated with the activation of glutamate receptors and non-receptor-mediated oxidative glutamate toxicity $[4,35]$. Recent studies have shown that glutamate-induced cytotoxicity could be mediated by oxidative stress, depletion of GSH, and down regulation of SOD activity that leads to apoptosis [18]. Reactive oxygen species are typically defined as molecules or ions formed by the incomplete one-electron reduction of oxygen. Elevated levels of ROS are well-known etiological factors associated with oxidative stress leading to cell death via apoptosis in a variety of cell types [20,36], and such effects can be blocked or delayed by a wide variety of antioxidants [30]. Such antioxidants are reported to scavenge free radicals by raising the levels of endogenous antioxidant defense systems such as glutathione peroxidase and glutathione reductase $[8,28]$. Consequently, pretreatment of the cells with C. aurantium extracts prior to glutamate exposure resulted in a significant decrease in ROS and MDA content as well as apoptotic cells. Citrus aurantium peel contains citral, limonene, and several citrus bioflavonoids, including hesperidin, neohesperidin, naringin, and rutin [29]. These compounds have been attributed with a range of properties. For example, naringin is believed to cross the blood brain barrier $[1,40]$ and to have antioxidant, anti-inflammatory, anti-hypercholesterolemic, anti-hypertensive, neuroprotective $[9,6,16]$, and anticonvulsant properties. It also increases the seizure latency to kainic acid administration [9]. Naringenin and hesperetin exhibit antiatherogenic properties by activating the peroxisome proliferator-activated receptor (PPAR) and up-regulating adiponectin expression [23]. Hesperidin, neohesperidin, and neohesperidin dihydro- chalcone, the most abundant species detected, are attributed antioxidant [14,19], anti-inflammatory $[10,12]$, and vasopressive and antiplatelet properties [24] and may be responsible for the anticonvulsant properties of the $C$. aurantium extract. However, the peels and seeds of citrus fruits are rich in nutrients and contain many phytochemicals with strong potential to be used in drug production or as food supplements $[7,21,25]$. Some studies showed that C. aurantium has direct antioxidant activity. For example, Karimi et al. (2012) reported that C. aurantium extract scavenges free radicals and exhibits ferric reducing potential, with values of $55.3 \%$ and $51.7 \%$, respectively [16]. The obtained results from pretreatment of cells with $C$. aurantium extracts demonstrated increased antioxidant capacity of cells prior to exposure to glutamate may be involved in cytoprotective properties of the extracts. In consistent with our results, other investigations also showed antioxidative properties of its bioactive constituents $[6,9]$.

In conclusion, our study demonstrated that C. aurantium has an apparently neuroprotective effect against glutamate oxidative damage through its antioxidant activity. However, further studies are required to elucidate its molecular mechanism before the clinical therapeutic application of these extracts.

\section{Acknowledgements}

This work was supported by the Office of the Vice Chancellor for Research and Technology of Mashhad University of Medical Sciences. The authors are gratefully acknowledged for this financial support.

\section{Disclosure}

Authors report no conflict of interest.

\section{References}

1. Ameer B, Weintraub RA, Johnson JV, Yost RA, Rouseff RL. Flavanone absorption after naringin, hesperidin, and citrus administration. Clin Pharmacol Ther 1996; 60: 34-40.

2. Aruoma OI, Landes B, Ramful-Baboolall D, Bourdon E, Neergheen-Bhujun V, Wagner KH, Bahorun T. Functional benefits of citrus fruits in the management of diabetes. Prev Med 2012; 54: S12-S16.

3. Assini JM, Mulvihill EE, Sutherland BG, Telford DE, Sawyez CG, Felder SL, Chhoker S, Edwards JY, Gros R, Huff MW. Naringenin prevents cholesterol-induced systemic inflammation, metabolic dysregulation, and atherosclerosis in Ldlr/mice. J Lipid Res 2013; 54:711-724. 
4. Bonfoco E, Krainc D, Ankarcrona M, Nicotera P, Lipton SA. Apoptosis and necrosis: two distinct events induced, respectively, by mild and intense insults with N-methyl-D aspartate or nitric oxide/superoxide in cortical cell cultures. Proc Natl Acad Sci U S A 1995; 92: 7162-7166.

5. Castleman M. The Healing Herbs: The Ultimate Guide to the Curative Power of Nature's Medicines. Bantam Books, New York 1995.

6. Chanet A, Milenkovic D, Manach C, Mazur A, Morand C. Citrus flavanones: what is their role in cardiovascular protection? J Agric Food Chem 2012; 60: 8809-8822.

7. Chede PS. Phytochemical analysis of Citrus sinensis peel. Int J Pharm Bio Sci 2013; 4: 339-343.

8. Gao Y, Zhang HW, Qiao HL, Wang W, Chang JB. Protective effect of 3-butyl-6-bromo-1(3H)-isobenzofuranone on hydrogen peroxide-induced damage in PC12 cells. Brain Res 2010; 1358: 239-247.

9. Golechha M, Chaudhry U, Bhatia J, Saluja D, Arya DS. Naringin protects against kainic acid-induced status epilepticus in rats: evidence for an antioxidant, anti-inflammatory and neuroprotective intervention. Biol Pharm Bull 2011; 34: 360-365.

10. Hamdan DI, Mahmoud MF, Wink M, El-Shazly AM. Effect of hesperidin and neohesperidin from bittersweet orange (Citrus aurantium var. bigaradia) peel on indomethacin-induced peptic ulcers in rats. Environ Toxicol Pharmacol 2014; 37: 907-915.

11. Hazell AS, Itzhak Y, Liu H, Norenberg MD. 1-Methyl-4-phenyl1,2,3,6-tetrahydropyridine (MPTP) decreases glutamate uptake in cultured astrocytes. J Neurochem 1997; 68: 2216-2219.

12. Ho SC, Kuo CT. Hesperidin, nobiletin, and tangeretin are collectively responsible for the anti-neuroinflammatory capacity of tangerine peel (Citri reticulatae pericarpium). Food Chem Toxicol 2014; 71: 176-182.

13. Hosseini A, Shafiee-Nick R, Mousavi SH. Combination of Nigella sativa with Glycyrrhiza glabra and Zingiber officinale augments their protective effects on doxorubicin-induced toxicity in h9c2 Cells. Iran J Basic Med Sci 2014; 17: 993-1000.

14. Hu L, Li L, Xu D, Xia X, Pi R, Xu D, Wang W, Du H, Song E, Song $Y$. Protective effects of neohesperidin dihydrochalcone against carbon tetrachloride-induced oxidative damage in vivo and in vitro. Chem Biol Interact 2014; 213: 51-59.

15. Hwang SL, Shih PH, Yen GC. Neuroprotective effects of citrus flavonoids. J Agric Food Chem 2012; 60: 877-885.

16. Karimi E, Oskoueian E, Hendra R, Oskoueian A, Jaafar HZE. Phenolic compounds characterization and biological activities of Citrus aurantium bloom. Molecules 2012; 17: 1203-1218.

17. Kazmierczak A, Strosznajder JB, Adamczyk A. $\alpha$-Synuclein enhances secretion and toxicity of amyloid beta Peptides in PC12 cells. Neurochem Int 2008; 53: 263-269.

18. Kritis AA, Stamoula EG, Paniskaki KA, Vavilis TD. Researching glutamate-induced cytotoxicity in different cell lines: a comparative/collective analysis/study. Front Cell Neurosci 2015; 9: 91.

19. Kumar A, Lalitha S, Mishra J. Possible nitric oxide mechanism in the protective effect of hesperidin against pentylenetetrazole (PTZ)-induced kindling and associated cognitive dysfunction in mice. Epilepsy Behav 2013; 29: 103-111.

20. Lan AP, Xiao LC, Yang ZL, Yang CT, Wang XY, Chen PX, Gu MF, Feng JQ. Interaction between ROS and p38MAPK contributes to chemical hypoxia-induced injuries in PC12 cells. Mol Med Rep 2012; 5: 250-255.

21. Lawal D, Bala JA, Aliyu SY, Huguma MA. Phytochemical screening and in vitro anti-bacterial studies of the ethanolic extract of Citrus Sinensis (Linn.) peel against some clinical bacterial isolates. International Journal of Innovation and Applied Studies 2013; 2: 138-145.

22. Li N, Liu B, Dluzen DE, Jin Y. Protective effects of ginsenoside Rg2 against glutamate-induced neurotoxicity in PC12 cells. J Ethnopharmacol 2007; 111: 458-463.

23. Liu L, Shan S, Zhang K, Ning Z, Lu X, Cheng, Y. Naringenin and hesperetin, two avonoids derived from Citrus aurantium up-regulate transcription of adiponectin. Phyther Res 2008; 1403: 1400-1403.

24. Majumdar S, Srirangam R. Solubility, stability, physicochemical characteristics and in vitro ocular tissue permeability of hesperidin: a natural bioflavonoid. Pharm Res 2009; 26: 1217-1225.

25. Mathew B, Jatawa SK, Tiwaari A. Phytochemical analysis of Citrus limonum pulp and peel. Int J Pharm Pharm Sci 2012; 4: 269-371.

26. Meiyanto E, Hermawan A, Anindyajati A. Natural products for cancer-targeted therapy: citrus flavonoids as potent chemopreventive agents. Asian Pac J Cancer Prev 2012; 13: 427-436.

27. Mulvihill EE, Huff MW. Citrus flavonoids and the prevention of atherosclerosis. Cardiovasc Hematol Disord Drug Targets 2012; 12: 84-91.

28. Nichols JA, Katiyar SK. Skin photoprotection by natural polyphenols: anti-inflammatory, antioxidant and DNA repair mechanisms. Arch Dermatol Res 2010; 302: 71-83.

29. Okwu DE. Citrus fruits: a rich source of phytochemicals and their roles in human health. Int J Chem Sci 2008; 6: 451-471.

30. Ozkan OV, Yuzbasioglu MF, Ciralik H, Kurutas EB, Yonden Z, Aydin M, Bulbuloglu E, Semerci E, Goksu M, Atli Y, Bakan V, Duran N. Resveratrol, a natural antioxidant, attenuates intestinal ischemia/reperfusion injury in rats. Tohoku J Exp Med 2009; 218: 251-258.

31. Park E, Pezzuto JM. Flavonoids in cancer prevention. Anticancer Agents Med Chem 2012; 12: 836-851.

32. Penugonda S, Mare S, Lutz P, Banks WA, Ercal N. Potentiation of lead-induced cell death in PC12 cells by glutamate: protection by $\mathrm{N}$-acetylcysteine amide (NACA), a novel thiol antioxidant. Toxicol Appl Pharmacol 2006; 216: 197-205.

33. Romagnolo DF, Selmin OI. Flavonoids and cancer prevention: a review of the evidence. J Nutr Gerontol Geriatr 2012; 31: 206-238.

34. Rosa-Falero C, Torres-Rodríguez S, Jordán C, Licier R, Santiago Y, Toledo Z, Santiago M, Serrano K, Sosa J, Ortiz JG. Citrus aurantium increases seizure latency to PTZ induced seizures in zebrafish thru NMDA and mGluR's I and II. Front Pharmacol 2015; 13: 284.

35. Seyfried J, Evert BO, Rundfeldt C, Schulz JB, Kovar KA, Klockgether T, Wullner U. Flupirtine and retigabine prevent L-glutamate toxicity in rat pheochromocytoma PC12 cells. Eur J Pharmacol 2000; 400: 155-166.

36. Tao L, Li X, Zhang L, Tian J, Li X, Sun X, Li X, Jiang L, Zhang X, Chen J. Protective effect of tetrahydroxystilbene glucoside on 6-OHDA-induced apoptosis in PC12 cells through the ROS-NO pathway. PLoS One 2011; 6: e26055. 
37. Walton HS, Dodd PR. Glutamate-glutamine cycling in Alzheimer's disease. Neurochem Int 2007; 50: 1052-1066.

38. Wang CJ, Hu CP, Xu KP, Yuan Q, Li FS, Zou H, Tan GS, Li YJ. Protective effect of selaginellin on glutamate-induced cytotoxicity and apoptosis in differentiated PC12 cells. Naunyn Schmiedebergs Arch Pharmacol 2010; 381: 73-81.

39. Weil ZM, Norman GJ, DeVries AC, Nelson RJ. The injured nervous system: a Darwinian perspective. Prog Neurobiol 2008 86: 48-59.

40. Zbarsky V, Datla KP, Parkar S, Rai DK, Aruoma OI, Dexter DT. Neuroprotective properties of the natural phenolic antioxidants curcumin and naringenin but not quercetin and fisetin in a 6-OHDA model of Parkinson's disease. Free Radic Res 2005; 39: 1119-1125. 